\title{
The Effect of Negative Celebrity Publicity and Celebrity Identification Toward Purchase Intention
}

\author{
Dhiajeng Hesti Prameswara ${ }^{1}$, Bertina Sjabadhyni ${ }^{2}$ \\ ${ }^{1,2}$ Faculty of Psychology, University of Indonesia, Depok, Indonesia \\ *E-mail: dhiajeng.hesti@ui.ac.id
}

\begin{abstract}
The purpose of this study is to examine the effect of negative celebrity publicity and celebrity identification on consumers' purchase intention. The negative celebrity publicity used in this study is a controversial news article about a celebrity who endorses a fictitious product. The consumers' level of celebrity identification divided into low vs. high identification. A 2 x 2 between-subject factorial design was conducted to 545 woman consumers aged 18-25 years old living in Jabodetabek. The result showed that both negative celebrity publicity and celebrity identification affect purchase intention. Participants who were exposed to the negative celebrity publicity had less purchase intention compared to participants who were not exposed to the negative celebrity publicity. Celebrity identification also predicts purchase intention, the participant who was highly identified with celebrity endorser showed greater purchase intention than those who were lowly identified. No interaction effect found between negative celebrity publicity and celebrity identification toward purchase intention. The implication of this study was practitioner should concern about these factors (negative celebrity publicity and celebrity identification) when using celebrity endorsement as a marketing strategy.
\end{abstract}

Keywords: celebrity endorsement, celebrity identification, negative celebrity publicity, purchase intention, online experiment

\section{Introduction}

The opportunity of selling is oftentimes predicted from the consumers' purchase intention (Morwitz, Steckel, \& Gupta, 2007). Purchase intention is a particularly popular attitudinal construct for consumers to rate a product (Spears \& Singh, 2004). Intention can be defined as motivational factor that influence individual's behavior (Ajzen, 1991). According to Schiffman and Wisenblit (2014), purchase intention is the measurement of consumer's tendency to buy goods or services. The higher the level of purchase intention, the higher consumers' tendency to buy the goods or services.

Companies are willing to proliferate purchase intention by using celebrity endorsement. According to McCracken (1989), celebrity endorsement is a form of advertisement which illustrates individual who enjoys public recognition and uses their recognition on behalf of a product by appearing with it in an advertisement. Celebrity endorsement is an effective marketing strategy because it will directly effect consumers' purchase intention (Gupta, Kishore, \& Verma, 2015) and sales performance (Elberse \& Verlaun, 2012). In Indonesia, the effect of celebrity endorsement is quite significant. This can be seen from MarkPlus Insight Instant Survey which shows about $68.4 \%$ of consumers in Indonesia have purchased particular products on account of the celebrity endorser of the product advertised (MarkPlus Inc, 2014). According to the survey, Indonesian consumers most strongly influenced by celebrity endorsement when buying face and beauty products (Markplus Inc, 2014).

Despite the beneficial aspects, celebrity endorsement has its own risk. Celebrity endorsement risks celebrities' personal matter, known as negative celebrity publicity. It becomes a risk because most of the celebrities' behaviors, statements, and comments become parts of their spotlights (Edwards \& LaFerle, 2009). Negative celebrity publicity defined as media's attention toward a negative disposition flaunted by a celebrity in their professional or personal life which may lead to disastrous consequences (Kasers \& Oelkers, 2008; Wilson, Stavros, \& Westberg, 2008).

When negative celebrity publicity occurred, most companies try to distance themselves from the celebrity endorser to avoid the transfer of 
unfavorable attitude from celebrity to the product advertised (Edwards \& LaFerle, 2009). For instance, when Ayu Tingting was involved in extramarital affair scandal with Raffi Ahmad, she was terminated from her contract endorsing Oppo smartphone (Arian, 2017). Termination also occurred to Luna Maya when she was dismissed as Lux's brand ambassador because of her porn video scandal which she faced at that time (Yogara, 2010).

Negative publicity by the media may harm consumers' evaluation of the product which celebrity endorsed. Thwaites, Lowe, Monks, and Barnes (2012) found that negative celebrity publicity lowers celebrity's credibility and reputation. Celebrity's credibility affects the appraisal and intention of the consumers positively (Pornpitakpan, 2004). In a research conducted by Till and Shimp (1998), it was found that negative celebrity publicity disrupts consumers' evaluation of the advertised product. Um (2013) added that negative celebrity publicity lowers consumers' purchase intention.

It is also supported by Um (2013) that the level of celebrity identification is an important factor which affects consumers' evaluation and purchase intention. According to Brown and Fraser (2004), celebrity identification is a process in which a person attempts to adopt values, belief, or behavior of renowned individual or popular character on media to imitate perceptible image or expose the relation with the celebrity. Celebrity identification may cause awareness, values, and behavior changes (Brown \& Fraser, 2004). The higher one's identification toward a celebrity, the bigger his/her tendency of adopting the values, belief, and behavior of the celebrity.

There could be an interaction effect between negative celebrity publicity and celebrity identification that could affect consumers' purchase intention. Research showed that consumers still purchase the advertised product due to their precedent admiration toward the celebrity (Fong \& Wyer, 2012). In addition, participants who extremely admired the celebrity have positive attitude despite the scandal involving the celebrity and will continue to buy the advertised products endorsed by the celebrity. Even though the news is being delivered negatively, many consumers do not really pay attention to negative aspect spread by the media. For the example, despite Ayu Tingting was reported having an affair with Raffi Ahmad, there were many people who still give her moral support (Supriyanto, 2016).

The purpose of this study is to examine the effect of negative celebrity publicity and celebrity identification towards purchase intention. The practical implication of this study is the results could become reference for marketing practitioner (e.g. Brand Manager) to concern about factors like negative publicity and celebrity identification when using celebrity endorsement a marketing strategy.

We interested to see if the consumers are exposed to negative celebrity publicity, will they show more negative attitude (shown by lower purchase intention) than the consumers that are not exposed to such publicity? We also interested to examine whether celebrity identification is a significant factor that affects consumers' purchase intention. We predict that the consumers who are highly identified with a celebrity endorser will show higher purchase intention than those who are lowly identified with celebrity endorser. This study also examines if there is an interaction effect between negative celebrity publicity and celebrity identification which impacts consumers' purchase intention. Therefore, the following hypothesis is proposed:

$\mathrm{H}_{1}$ : Consumers who are exposed to negative celebrity publicity will show lower purchase intention than consumers who are not.

$\mathrm{H}_{2}$ : Consumers who have high level of celebrity identification will show higher purchase intention than those who have low level of celebrity identification.

$\mathrm{H}_{3}$ : There is an interaction effect between the exposure of negative celebrity publicity and the level of celebrity identification that affects purchase intention.

\section{Methods}

Sample. There are 545 participants that consist of 18 to 25-year-old women from Jabodetabek area. Participants were obtained from incidental sampling. Participants were all female because research by Edwards and LaFerle (2009) found that gender congruence between consumers and the celebrity endorsers affects consumer attitudes, where negative celebrity publicity will have more impact when celebrity endorser have the same gender as consumers. The online survey link is shared based on participants' criteria. Three lucky participants will win MAP voucher worth Rp 100.000. 
Research Design. This study was conducted using 2 (Negative Celebrity Publicity vs. Neutral) x 2 (High vs. Low Celebrity Identification) between-subject experimental design. The effect of negative celebrity publicity will be evaluated by comparing the participants who are exposed to negative celebrity publicity with that of who is not. This research also observed the effect of celebrity identification level toward purchase intention by comparing the customers with high and low level of identification. The participants were divided into low and high identification level using median split. Furthermore, this research also examined the interaction between negative celebrity publicity exposure and the level of celebrity identification toward purchase intention.

Instrument and Measurement. Researcher used purchase intention measurement by Junghwa (2013) that had been adapted by Yusuf (2014). The measurement consisted of 5 item in which participants were asked to conceive themselves at a shop to buy a particular product; they were asked to rate and relate themselves from very low to very high to 7-point-Likert-scale; "The chance to purchasing Duchi perfume is...", "If I were going to buy a perfume, I would consider buying Duchi perfume", "The probability that I would consider buying Duchi perfume is...", "I am sure to buy Duchi perfume", and "My willingness to purchase Duchi perfume is..." $(\alpha=.93)$.

Consumers' identification level toward the celebrity was measured by Celebrity Identification Scale (Lammie, 2007). This measurement consists of 10 items of 7-point scale, from strongly agree to strongly disagree, such as: "I like (Celebrity X)", "I can easily relate to (Celebrity X)", "I think (Celebrity $\mathrm{X})$ as a good friend", "I have no doubt (Celebrity X) and I would work well together", "(Celebrity X) is a personal role model", "Learning the life story of (Celebrity X) is a lot of fun", "I try to keep up with news about (Celebrity X)", "I am interested in the details of (Celebrity X)'s life", "I often feel compelled to learn the personal habits of (Celebrity $\mathrm{X})$ ", and there is one reversed item; "I do not have any feelings about (Celebrity X)" $(\alpha=.83)$.

We use Celebrity Credibility Scale (Ohanian, 1990), which consisted of 6 items of 7-point-bipolar-scale to measure attractiveness, trustworthiness, and expertise of a celebrity $(\alpha=0.89)$. Participants were being shown fictitious advertisement to be scaled, from strongly disagree to strongly agree with their opinion whether the celebrity is Honest, Trustworthy, Expert, Attractive, and Classy. This scale is used as a manipulation check. Participants who were exposed to celebrity negative publicity were expected to give lower evaluation of celebrity credibility rather than participants who were not exposed to negative celebrity publicity.

Procedure. We conducted several pilot tests to determine the celebrity endorser, the fictitious product that will be advertised as a stimuli, and the negative celebrity publicity that will be used as a manipulation.

\section{Preparation Phase}

The first pilot test was conducted to choose celebrity endorser and conduct survey to find out the scandal prevalence or negative celebrity publicity. There were 10 Indonesian celebrities with the most followers on Instagram that are chosen: Ayu Tingting, Syahrini, Laudya Chyntia Bella, Prilly Latuconsina, Julia Perez, Luna Maya, Raisa Andriana, Chelsea Olivia, Agnez Monica, and Zaskia Sungkar. These celebrities were measured by their familiarity, likeability, and credibility (trustworthiness, expertizes, and attractiveness) as a celebrity by 51 participants. The participants were also asked to mention negative publicity regarding these celebrities. As a result, Agnez Monica becomes celebrity endorser, for she had the highest average score. She was accused of her performance which disrespects Saman dance. The news was chosen because there was only one participant who came up with such news. This indicates the fact that most individuals disremembered or did not know about it. Thus, participants were expected not to have association with the news in order to undermine her credibility as celebrity endorser.

The second pilot study was conducted to choose the advertised product. Based on Markplus Insight Instant Survey (Markplus, 2014), result showed that face and body products were the number one product category that most strongly influenced by celebrity endorsement among Indonesian consumers. Therefore, this study uses fictitious face and body products advertisement as a stimulus. This baseline pretest study asked to participants the congruence between Agnez Monica and face and body products using 7-point-bipolar-scale ( 1 = strongly unsuitable, 7 = very suitable) adapted from Ilicic and Webster (2011) by the question "Is X (celebrity endorser) suitable to advertise product A (choice of face and beauty products)". Product options which were measured in terms of congruence were soap, facial wash, scrub, body lotion, deodorant, sunblock, shampoo, perfume, powder, lipstick, and face cream. The perfume was considered the most suitable 
product to be endorsed by Agnez Monica, and it was qualified for this study due to the highest mean score among all products. The result of second pilot study was adapted into a fictitious advertisement of Agnez Monica promoting a perfume product; "Duchi". The name of the fictitious brand was chosen by translating the word "perfume" into Belarussian on google translate. The advertisement included Agnez Monica's signature and the product's tagline. The advertisement included neither the price nor other offers. The advertisement was included below.

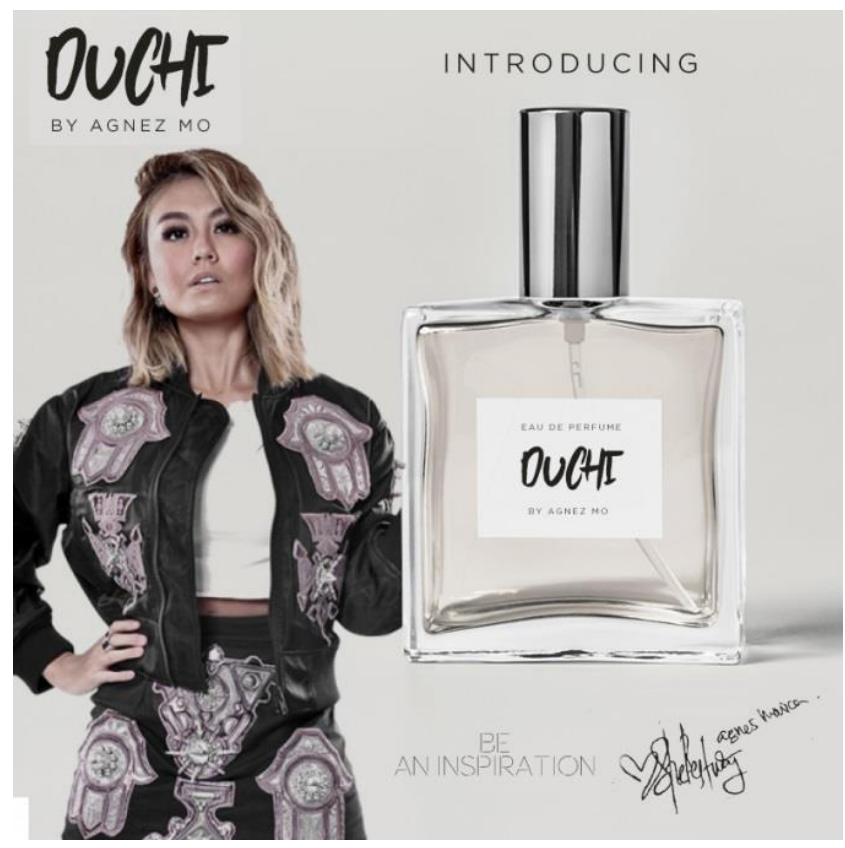

Figure 1. Fictitious Ads by Agnez Monica

The third pilot study was conducted to examine the advertisement and negative celebrity publicity, whether or not it looks credible. In addition, this survey was conducted to ascertain participants' awareness toward the advertisement beforehand. The result showed that majority of the participant believes that the advertisement was credible, and $100 \%$ of them have not seen the advertisement before. Several participants added that the news article was quite unreadable. From this result, we changed few parts and the font into larger size.

\section{Experiment Phase}

The research was conducted through online questionnaire from survey.ui.ac.id (http://survey.ui.ac.id/399139) platform. The main study was done through online survey where its first page shows a welcome message. The participants were required to read and fill the informed consent. If they agree to participate in the research, they may choose the 'Yes' button. However, if they disagree, they may choose 'No' and leave the page.

After that, the participants who clicked 'yes' button will be randomly divided into a group which was either exposed or not exposed to negative celebrity publicity. The group which was not exposed to negative celebrity publicity will be shown a fictitious advertisement of Agnez Monica. Then they were required to fill a questionnaire that measures celebrity identification. After that, the participants were asked to write their opinions about the brand ambassador and their intentions on buying Duchi perfume as a manipulation check.

In the second group (exposed to negative celebrity publicity) the participants will also be shown a fictitious advertisement and the same questionnaire as the previous group. However, there was a difference where this group will be given negative news about Agnez Monica after they finished filling the questionnaire about celebrity identification. After that, the participants were asked about their opinion on the brand ambassador and their intentions on buying the advertised product.

On the next part, the participants were asked questions regarding the article as an awareness check. If the participants read the article, they will be shown the following question such as, "In your opinion, what is the conclusion of the article?" Also, the level of confidence in the article was measured by asking "Do you trust the article?". Then there were choices for the answers, such as "Strongly agree," "Agree," "Somehow agree," "Somehow disagree," "Disagree," and "Strongly disagree." For the participants who were not provided with the article, they may choose "No" and continue to the next part.

For the next part, the participants were asked to fill their personal information. Before the participants left the online survey page, there was an explanation that the advertisement they saw earlier is fictitious, and it was only the part of the research. If they understand, they may choose "Yes" and click the "Submit" button to end the survey. The explanation was intended to avoid any negative impact on the celebrity. The access to the survey was immediately closed after data gathering period is ended. This is intended to avoid the negative news to be more widespread and to prevent any negative impacts on celebrity's reputation. On the last page, there was a thank you note from the researcher and information 
regarding the winner of the draw, which will be contacted through the personal information they fill earlier.

\section{Results}

\section{Manipulation Check}

Table 1.

Manipulation Check Result Using Independent Sample t-Test

\begin{tabular}{cccccc}
\hline & $\begin{array}{c}\text { Not Exposed } \\
\text { to Negative } \\
\text { Celebrity }\end{array}$ & $\begin{array}{c}\text { Exposed to } \\
\text { Negative } \\
\text { Celebrity }\end{array}$ & \\
$\begin{array}{c}\text { Dependent } \\
\text { Variable }\end{array}$ & $\begin{array}{c}\text { Publicity } \\
(\mathrm{N}=327)\end{array}$ & $\begin{array}{c}\text { Publicity } \\
(\mathrm{N}=271)\end{array}$ & \\
& $M$ & $S D$ & $M$ & $S D$ & $t$ \\
\hline $\begin{array}{c}\text { Celebrity's } \\
\text { Credibility }\end{array}$ & 28.34 & 5.43 & 25.92 & 5.85 & $4.94^{*}$ \\
\hline p $<0.05$ & & & & & \\
\end{tabular}

\section{Hypothesis Testing}

Two-way Analysis of Variance (ANOVA) used to get the hypothesis result of the research.

Table 2.

Means and Standard Deviation for Consumer's Purchase Intention

\begin{tabular}{cccccc}
\hline & \multicolumn{2}{c}{ Group } & & & \\
\cline { 2 - 4 } $\begin{array}{c}\text { Dependent } \\
\text { Variable }\end{array}$ & $\begin{array}{c}\text { Exposure } \\
\text { Level }\end{array}$ & $\begin{array}{c}\text { Level } \\
\text { of CI }\end{array}$ & $\begin{array}{l}\text { Mean } \\
(M)\end{array}$ & $(S D)$ & $N$ \\
\hline Purchase & Not & Low & 12.83 & 5.54 & 155 \\
Intention & Exposed & High & 17.65 & 5.24 & 172 \\
& & Total & 15.37 & 5.89 & 327 \\
& & Low & 11.7 & 5.01 & 116 \\
& & High & 16.93 & 5.66 & 102 \\
& & Total & 14.15 & 5.92 & 218 \\
& Total & High & 17.38 & 5.34 & 273 \\
& & Low & 12.35 & 5.40 & 272 \\
& & Total & 14.88 & 5.93 & 545 \\
\hline
\end{tabular}

Table 3.

ANOVA Results for The Effect of Negative Celebrity Publicity and Celebrity Identification Toward Purchase Intention

\begin{tabular}{cccccc}
\hline $\begin{array}{c}\text { Dependent } \\
\text { Variable }\end{array}$ & Source & df & F & Sig. & $\eta$ \\
\hline & $\begin{array}{c}\text { Negative } \\
\text { Celebrity } \\
\text { Publicity (A) } \\
\text { Celebrity }\end{array}$ & 1 & 3.89 & $0.04 *$ & 0.01 \\
$\begin{array}{c}\text { Purchase } \\
\text { Intention } \\
\text { Identification } \\
(\mathrm{B})\end{array}$ & 1 & 114.61 & $0.00 *$ & 0.18 \\
$\mathrm{~A} \times \mathrm{B}$ & 1 & 0.19 & 0.66 & 0 \\
\hline $\mathrm{R}^{2}=0.187,(*) \mathrm{p}<0.05$ & & & &
\end{tabular}

2x2 Factorial ANOVA was implemented to examine the mean difference between the group that was exposed to negative celebrity publicity and the group that was not exposed. According to Table 3, there is a significant effect of negative celebrity publicity on purchase intention, $\mathrm{F}(1,541)=3.89, \mathrm{p}<.05, \mathrm{n}_{\mathrm{p}}{ }^{2}=0.01$. The group that was exposed to negative celebrity publicity $(M=14.15 ; S D=5.92)$ has a lower purchase intention rate compared to the group that was not exposed to negative celebrity publicity $(M=15.7$; $S D=5.89)$. As a result, $\mathrm{H} 1$ was supported.

The result also showed a significant effect of negative celebrity publicity on purchase intention, $\mathrm{F}(1,541)=114.61, \mathrm{p}<.05, \mathrm{n}_{\mathrm{p}}{ }^{2}=0.18$. It was found that the group with high identification level $(M=17.38$; $S D=5.34$ ) has a higher purchase intention compared to the group with low identification level $(M=12.35$; $S D=5.40)$. Thus, $\mathrm{H} 2$ was supported.

Finally, there was no interaction effect between negative celebrity publicity and celebrity identification that affects purchase intention, $\mathrm{F}(1$, $541)=0.195, \mathrm{p}=0.659, \mathrm{n}_{\mathrm{p}}{ }^{2}=0$. Figure 2 showed that the interaction between the exposure of negative celebrity publicity and the level of celebrity identification that affects purchase intention did not exist. These two factors affect purchase intention independently. Therefore, H3 was not supported. 


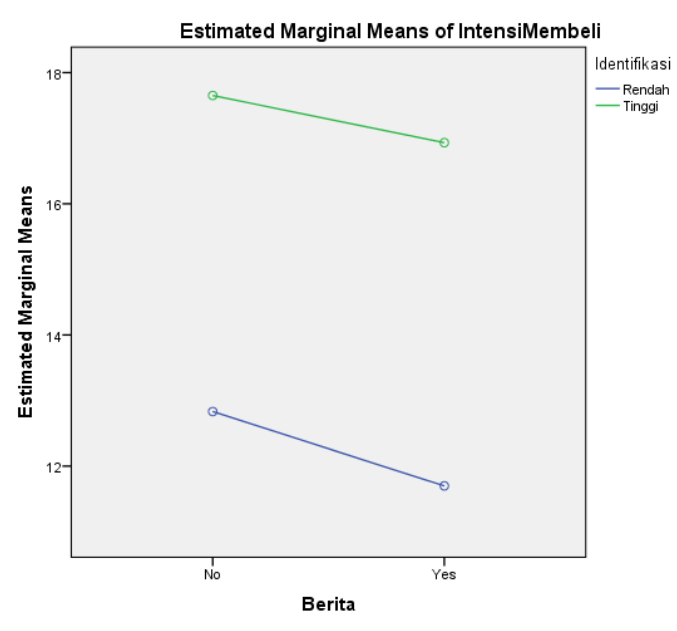

Figure 2. Interaction Graphic Between Negative Celebrity Publicity and Celebrity Identification

\section{Discussion \& Conclusion}

Discussion. The result shows that negative celebrity publicity affects consumers' purchase intention. Consumers with negative celebrity publicity exposure showed a lower purchase intention compared to consumers who did not show the negative celebrity publicity. The result corresponds to the research by Um (2013) which showed that negative news about celebrity results in a lower purchase intention. This result can be explained by meaning transfer model. In this model, the meaning that is perceived in a celebrity can be transferred to the product (McCracken, 1989). We suspect that if the celebrity perceived to be somewhat negative, the negative meaning itself can be transferred to the product that they endorse. Thus, it can result in a more negative purchase intention. Based on the study, it is better for the company to put a regulation in the employment contract in case the celebrity got involved in a scandal or negative celebrity publicity. Moreover, it is also better for the celebrity's management to preserve their celebrity's image and keep them off a scandal.

The result also showed that celebrity identification level affects purchase intention. Consumers with high level of celebrity identification showed a higher purchase intention compared to consumers with low level of celebrity identification. This result was in line with the research conducted by Um and Lee (2015) which stated that people who have a high level of identification with a celebrity endorser show higher purchase intention compared to those who have a low identification level. According to Brown and Fraser (2004), identification of a celebrity influences person's awareness, values, and behaviors. The higher his/her identification level to a celebrity, the possibility for that person to adopt the values, beliefs, and behaviors that consistently demonstrated by celebrity may also be greater (Brown and Fraser, 2004). It is common for a person with a high level of identification to adopt the behavior and to have a higher probability of purchase when looking at a product advertised by the celebrity. It is shown that celebrity identification level influences purchase intention, and it becomes a consideration for marketing practitioners to choose celebrity endorsers that are highly identified by the community. The result of this study can be a basis for conducting a more in-depth survey to find out who the most influential celebrities with high identification level are. This research can also become a consideration for advertising agencies who want to use celebrities in creating their advertisement.

This research revealed that there is no interaction effect between negative celebrity publicity exposure and celebrity identification level toward consumers' purchase intention. We suspect that interaction lies in how consumers attribute negative news. There are two types of attribution: internal attribution and external attribution. Heider (1958) stated that internal attribution is a condition when consumers assume that negative event happens because of internal factors, such as personality and the character of the celebrity themselves. On the other hand, external attribution is defined as when the consumers consider any negative events are related with outside factors, such as situations or conditions that cause the celebrity to behave so, or the social circumstances surrounding celebrity's action. A research by Um and Lee (2015) found that consumers' attribution type influences purchase intention, and it also interacts with consumers' identification level on the celebrity. The result exposes that internal attribution is more likely to cause negative evaluation compared to external attribution. Consumers who have high identification level tend to attribute negative events about celebrities on external factors whereas consumers who have low identification level will tend to attribute events on internal factors (Um \& Lee, 2015). In this case, when the consumers have a high identification level, they will tend to blame the negative events due to situational factors. In contrast, consumers who have a low identification level tend to blame negative events on the self-factor of the celebrity. Therefore, the interaction lies not in the presence or absence of negative celebrity 
publicity exposure, but on the type of attribution of the consumer in viewing the negative celebrity publicity.

The result showed that the relationship between negative celebrity publicity and purchase intention only had minor effect. Based on the calculation, the effect of negative celebrity publicity on purchase intention has a small effect. Because of that, it turns out that the attribution of consumers in viewing negative news affect the purchase intention (Um \& Lee, 2015). When consumers consider negative events are caused by factors within the celebrity or internal attribution, the consumer will have a more negative evaluation of the product (Um \& Lee, 2013). The researcher suspects the news that is used in this research is less to blame the celebrity or less attributed internally by participants. This leads to the negative celebrity publicity effect on purchase intention becomes small. Further research might be able to measure consumers' attribution and use the news that would likely to be more attributed internally by consumers. The measurement of consumer attribution must be done so that the negative celebrity publicity effect on the purchase intention is caused by the same type of attribution.

There are some limitations in this study. This research uses Celebrity Identification Scale measurement (Lammie, 2007) that has not been proven its validity when using a different language. Further research may test the external validity of the Celebrity Identification Scale by comparing to other instruments in the Indonesian language that measures similar constructs, such as the attachment toward a celebrity or Parasocial Interaction Scale.

This research also categorizes the level of celebrity identification by sorting the total score of the participants' Celebrity Identification Scale and dividing the groups by median split. This becomes the researcher's consideration that the level of celebrity identification may not be much different. Therefore, further research can use participants with different characteristics. Further research can also categorize the level of identification by using participants who are the members of celebrity fans and those who are not. This intends to immediately get participants with a much different level of identification.

Conclusions. The results show that negative celebrity publicity and celebrity identification affects consumers' purchase intention. This study shows that the group of participants who were exposed to negative celebrity publicity shows lower purchase intention compared to the participants that were not exposed to negative celebrity publicity.

The results of this study also indicate that the level of celebrity identification is associated with consumers' purchase intention. Consumers who have high level of celebrity identification show higher purchase intention than consumers who have low level of celebrity identification.

Furthermore, the results show no interaction effect between the two factors (negative celebrity publicity and celebrity identification) that affect in purchase intention. This study shows that there is no interaction between negative celebrity publicity exposure and celebrity identification level which influence purchase intention. It is known from the research that both factors influence purchase intention independently.

\section{References}

Ajzen, I. (1991). Theory of planned behavior. Organizational behavior and human decision process, 50(1), 179-211.

Arian. (2016, November 5). Isu miring dengan raffi membuat ayu ting ting "didepak" dari perusahaan ini, benarkah?. Fiwwit.com. Retrieved on 27th May 2017 from http://www.fiwwit.com/2016/11/05/isu-miring-raffimembuat-ayu-ting-ting-didepak-perusahaan-benarkah/

Brown, W. J., \& Fraser, B. P. (2004). Celebrity identification in entertainment-education. Dalam A. Singhal, M. J. Cody, E. M. Roger, \& M. Sabido, Entertainment-education and social change (pp. 97-115). New Jersey: Lawrence Erlbaum Associates.

Edwards, S. M., \& La Ferle, C. (2009). Does gender impact the perception of negative information related to celebrity endorsers?. Journal of Promotion Management, 15(2), 2235. DOI: $10.1080 / 10496490902837940$.

Elberse, A., \& Verleun, J. (2012). The economic value of celebrity endorsements. Journal of Advertising Research, 52(2), 149-165. DOI: 10.2501/JAR-52-3-149165.

Fong, C. P. S., \& Wyer, R. S. (2012). Consumers' reactions to a Celebrity Endorser Scandal. Psychology \& Marketing, 29(11), 885-896. DOI: 10.1002/mar.20571

Gupta, R., Kishore, N., \& Verma, D. P. S. (2015). Impact of celebrity endorsements on consumers' purchase intention: A study of Indian consumers. Australian Journal of Bussiness and Management Research, 5(3), 1-15.

Heider, F. (1958). The Psychology of Interpersonal Relations. New York: Wiley.

Ilicic, J., \& Webster, C. M. (2011). Effects of multiple endorsements and consumer-celebrity attachment on attitude and purchase intention. Australasian Marketing 
Journal, 19(4),

230-237.

10.1016/j.ausmj.2011.07.005.

Junghwa, S. (2013). Do Lower Prices Always Increase Willingness to Purchase?A Comprehensive Understanding Toward The Role of Perceived Price. University of North Carolina.

Kasers, K., \& Oelkers, D. B. (2008). Sports and Entertainment Marketing. Ohio: Thomson South-Western.

Markplus Inc. (2014). Celebrity endorsement - it is worth it but not always. Diakses pada 29 Mei 2017 dari http://markplusinsight.com/article/detail/72/celebrityendorsement---it-is-worth-it-but-not-always

McCracken, G. (1989). Who is celebrity endorser? Cultural foundations of the endorsement process. Journal of Consumer Research, 16(3), 310-321.

Morwitz, V. G., Steckel, J. H., \& Gupta, A. (2007). When do purchase intentions predict sales?. International Journal of Forecasting, 23(3), 347-364.

DOI: /10.1016/j.ijforecast.2007.05.015.

Ohanian, R. (1990). Construction and validation of a scale to measure celebrity endorsers' perceived expertise, trustworthiness, and attractiveness. Journal of Advertising, 19(3), 39-52.

Pornpitakpan, C. (2004). The effect of celebrity endorsers' perceived credibility on product purchase intention: The case of Singaporeans. Journal of International Consumer Marketing, 16(2), 55-74. DOI: 10.1300/J046v16n02_04

Schiffman, L. G., \& Wisenblit, J. (2015). Consumer Behavior (11th ed.). Harlow, UK: Pearson Education Limited.

Spears, N., \& Singh, S. N. (2004). Measuring attitude toward the brand and purchase intentions. Journal of Current Issues \&
Research in Advertising, 26(2), 53-66. DOI: 10.1080/10641734.2004.10505164.

Till, B. D., \& Shimp, T. A. (1998). Endorsers in advertising: the case of celebrity information. Journal of Advertising, 27(1), 67-81. DOI: 10.1080/00913367.1998.10673543.

Thwaites, D., Lowe, B., Monkhouse, L. L., Barnes, B. R. (2012). The impact of negative publicity on celebrity ad endorsement. Psychology \& Marketing, 29(9), 669-673. DOI: 10.1002/mar.20552

Um, N. H. (2013). Celebrity scandal fallout: How attribution style can protect the sponsor. Psychology \& Marketing, 30(6), 529-541. DOI: 10.1002/mar.20625.

Um, N. H., \& Lee, W. N. (2015). Does culture influence how consumers process negative celebrity information? Impact of culture in evaluation of negative celebrity information. Asian Journal of Communication, 25(3), 327347. DOI: 10.1080/01292986.2014.955860.

Wilson, B., Stavros, C., \& Westberg, K. (2008). Player transgression and the management of the sport sponsor relationship. Public Relations Review, 34(1), 99-107. DOI: 10.1016/j.pubrev.2008.03.012

Yogara, B. (2010, June 14). Luna maya resmi berhenti sebagai brand ambassador lux. Tabloid Bintang. Retrieved on 13 March 2017 from http://archive.tabloidbintang.com/berita/gosip/3706-lunamaya-resmi-berhenti-sebagai-brand-ambassador-lux.html

Yusuf, M. (2014). Hubungan Antara Persepsi Kualitas, Persepsi Harga, dan Intensi Membeli pada Produk Fashion, Bermerek Asli Indonesia (Bachelor Thesis, Universitas Indonesia Depok, Indonesia). 